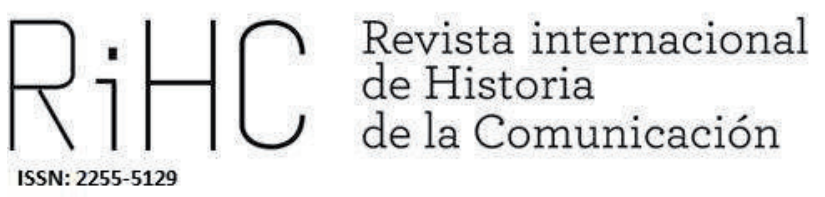

\title{
LADY WHISTLEDOWN EN SEVILLA: DE LA CONDESA DE BASSANVILLE A FERNÁN CABALLERO, PIONERAS EN LA CRÓNICA DE SOCIEDAD DEL XIX
}

Lady Whistledown in Seville: from Countess of Bassanville to Fernán Caballero, pioneers on the society chronicle of nineteenth century

DOI: http://dx.doi.org/10.12795/RiCH.2021.i16.02

Recibido: 31-3-2021

Aceptado: 5-4-2021

Publicado: 30-6-2021

Elena María Benítez-Alonso

Universidad de Sevilla, España

ebalonso@us.es

ORCID (I) 0000-0002-2167-144X 
Resumen: La ya popular serie de televisión Los Bridgerton, producida por la plataforma Netflix, ha traído a la actualidad el no poco relevante, aunque tampoco suficientemente valorado, papel de la mujer como cronista de sociedad en los albores de la prensa inglesa decimonónica. Más allá de la polémica sobre su discutida fidelidad histórica (habría que diferenciar aquí entre ficción "histórica" y "de época"), lo cierto es que el éxito de la trama se debe en gran medida al hecho de ser mostrada a través de los epistolares society papers de Lady Whistledown, personaje de ficción que se nutre, no obstante, de auténticos referentes históricos. Es el caso de Mrs. Crackenthorpe, columnista inglesa de principios del siglo XVIII especializada en los ecos de sociedad, que recogía desde The Female Tatler. A mediados del mismo siglo y como observadora moral de la sociedad, en España tenemos a La Pensadora Gaditana, Beatriz Cienfuegos, mientras que, ya avanzado el XIX, encontramos una crónica de la alta sociedad de autoría femenina más adentrada en lo informativo que, en la prensa sevillana, presenta un campo prácticamente inexplorado en el que hallamos, sin embargo, notorias firmas, como la de la Condesa de Bassanville o la de Fernán Caballero.

Palabras clave: Crónica de sociedad, prensa sevillana, autoras pioneras, siglo XIX, Los Bridgerton

\begin{abstract}
Produced by the platform Netflix, the already popular television series The Bridgerton has put up to date the not little relevant although not sufficiently valued woman's rol as a society chronicler at the dawn of the nineteenth century English press. Beyond the controversy over its disputed historical fidelity (it would be necessary to differentiate here between "historical" and "period" fiction), the truth is that the success of the plot is largely because of it is shown through the epistolary society papers by Lady Whistledow's, a fictional character who is based, however, on authentic historical references. This is the case of Mrs. Crackenthorpe, an English columnist from the early eighteenth century specializing in the echoes of society. She collected them in The Female Tatler. In the middle of the same century Beatriz Cienfuegos appeared in Spain with La Pensadora Gaditana as a moral observer of society and there is a female authorship chronicle of the high society that is more focused on the informational in the late nineteenth century. In Sevillian press it presents a practically unexplored field in which we have noticed, however, notorious signatures, such as that of Condesa de Bassanville or that of Fernán Caballero.
\end{abstract}

Keywords: Society chronicle, Sevillian press, pioneer women authors, nineteenth century, The Bridgerton

\title{
Introducción
}

En torno a 1833, mientras en España se abría paso una nueva y esperanzadora etapa para la sociedad y la prensa liberal ante el ocaso del absolutismo del reinado de Fernando VII, en los aún incipientemente emergentes Estados Unidos, concretamente en Connecticut, se difundía la publicación de The Open Country of Woman's Heart, un 
muy peculiar mapa, "a campo abierto del corazón de la mujer", naturalmente no muy anatómico y sí bastante más político (sobre todo correcto, en correlación con el tradicional modelo de ángel del hogar decimonónico) que físico. Su anónima autora firmaba con el no poco usual By a Lady bajo al auspicio editorial de los hermanos Kellog de Hartford. En esta cuidada cartografía de la True Womanhood o "verdadera feminidad" (O'Reilly, 1883), como estereotipo emocional de género, se detallaban las finas líneas entre "Land of Coquetry" ("Tierra de la Coquetería") y "Land of Love of Dress" ("Tierra del Amor al Vestido"), territorios también fronterizos con "Land of Love of Admiration" ("Tierra del Amor por la Admiración"), "Land of Love of Display" ("Tierra del Amor a la Exhibición") o "Sea of Wealth" ("Mar de la Riqueza"), plasmándose gráficamente y de forma más que elocuente el ideal de mujer que se hacía prevalecer en el siglo XIX y advirtiéndose también con ello del peligro de traspasar ciertos límites. Se popularizaba así un atractivo concepto de litografía ${ }^{1}$ que implicaba un eficaz adoctrinamiento mediático de la sociedad, especialmente de su componente femenino, en consonancia con los principios anglosajones vigentes, en general, tanto en Inglaterra durante el periodo de Regencia (que marca la transición hacia el XIX y se extiende hacia las casi cuatro primeras décadas del siglo) y en la posterior época victoriana (que se prolonga hasta el tránsito al siglo XX), como en Estados Unidos a lo largo de la centuria decimonónica. Se imponía además la vigencia de un modelo que, sin embargo, con notables excepciones, tendría asimismo gran repercusión en España y en cuyo contexto la crónica de sociedad, y de autoría femenina, experimentaría, como veremos en el desarrollo de esta investigación, un considerable auge, a pesar de que el papel desempeñado por la mujer en la prensa ha pasado prácticamente desapercibido, hasta hace unas décadas, para la historiografía tradicional. La importancia del modelo de ángel del hogar en España es objeto, de hecho, de numerosos estudios, lo que se manifiesta en trabajos de autores como Sánchez Llama (2000), que resulta asimismo de especial interés al profundizar en las colaboraciones en la prensa de las autoras isabelinas, aquellas que protagonizaron el auge de la mujer periodista-escritora en las publicaciones españolas decimonónicas. Pero nos situamos ante un campo que se halla prácticamente inexplorado en el caso de la prensa sevillana, en el que encontramos, no obstante, notorias firmas en la crónica de sociedad, como la de la Condesa de Bassanville o la de Fernán Caballero.

De ahí que estimemos necesario revalorizar este tipo de publicaciones a través del análisis de textos que consideramos exponentes de este género en las que se constituyen como autoras pioneras, en el siglo XIX, de notables cabeceras como la Revista de Ciencias, Literatura y Artes (1855-1860). Se trata, principalmente, de textos de crónica de sociedad entendida, en esos momentos, como información, con el estilo un tanto personal del autor (en nuestro caso de la autora), sobre la realeza, aristocracia y altas esferas, en general, sus costumbres, protocolos y sus modas. Pero también de

\footnotetext{
${ }^{1}$ Actualmente accesible a través de la galería en línea de la Sociedad Histórica de Connecticut.
} 
textos de crónica costumbrista más próximos a los de la crítica moral del siglo XVIII, aunque en un sentido más favorable al poder y diferenciada del concepto de crónica social, que se basa en temas más acordes con el periodismo social, referido a los sucesos acontecidos a componentes, principalmente, de otros estratos de la sociedad ${ }^{2}$. Centrándonos en el caso sevillano, abordamos pues este trabajo desde una perspectiva comparatista entre el modelo anglosajón y el español, como fruto de la significativa interrelación entre ambos espacios, consecuencia a su vez de los fenómenos de circulación de ideas que se produjeron ya en las primeras décadas del siglo XIX, desde el exilio inglés de los liberales españoles a los movimientos independentistas de las antiguas colonias españolas en América ${ }^{3}$. Recurrimos en nuestra investigación a los fondos hemerográficos de la Universidad de Sevilla (Fondo Antiguo) o de la Hemeroteca Municipal de esta ciudad para llevar a cabo la búsqueda y selección de referentes de la crónica de sociedad de firma femenina en la prensa sevillana del XIX, analizando especialmente publicaciones como la ya mencionada Revista de Ciencias, Literatura y Artes (1855-1860) y la más antigua Revista Andaluza (1841).

En ellas, como en el caso de notorias publicaciones anglosajonas de la época, descubriremos que no es de extrañar el interés que despertaba la información de las actividades de las clases altas en un mundo en el que, en sintonía con los valores establecidos, era esencial el ejemplo de los referentes sociales, pero en los que podía resultar más interesante la manifestación de la condición humana a través de sus errores; un mundo en el que se invitaba a llevar "una vida de fe" y en la que, como recoge el ilustrativo tratado The Mirror of True Womanhood: A Book of Instruction for Women in the World del ya referido reverendo O'Reilly, "sobre todas las cosas" se pedía a la mujer que amara "la abnegación y el propio sacrificio", y las "formas heroicas y las virtudes de nuestros antepasados" ("living a life of faith, loving above all things selfdenial and self-sacrifice, fondly attached to the heroic ways and virtues of our ancestors" (1883: X). Un mundo en el que se trataba, en definitiva, de imponer la preponderancia de una "cultura de la domesticidad" (Culture of Domesticity o Cult of Domesticity), en las recientes palabras de autores como Keister y Southgate (2012), centrada en "la verdadera feminidad" de O'Reilly, que casi un siglo después, y aludiendo a su propio patriarcal manual de comportamiento femenino, ya había sido analizada como Culture of True Womanhood, en relación con el sistema de valores predominante entre las clases media y alta, en Inglaterra y Estados Unidos durante el siglo XIX (Welter, 1966). Un sistema de valores en cuya difusión y masiva aceptación desempeñaron un papel esencial (151) los medios de comunicación del momento (a través de las revistas

\footnotetext{
${ }^{2}$ En este sentido, es importante recordar que más allá de la crónica volcada en la denuncia social, se encuentra la que trata historias de personajes de la alta sociedad, abordados no pocas veces con la pluma irónica del periodista (Aguilar, 2019).

3 Para profundizar en esta cuestión, ver trabajos como los de Durán López (2015), Fernández (2015) o Ruiz Acosta (2016).
} 
femeninas, anuarios de regalo y la literatura religiosa de la época), y que consideraba como "mujeres verdaderas" a aquellas que no ambicionaban más allá de convertirse en el centro del núcleo familiar como auténtica y poderosa "luz del hogar" ("candle power", a la que Welter se refiere en la página 152, y "the light of the domestic hearth", en la $165)^{4}$; a aquellas que poseían (y exhibían) "las cuatro virtudes cardinales", en clara correspondencia con los cuatro puntos que debían guiar el mapa de su corazón: por un lado, la piedad y la pureza; por otro, por supuesto, las ya señaladas domesticidad y sumisión. La manifestación (y ostentación) de estas virtudes podía decidir incluso el futuro de una mujer (madre, hija, hermana o esposa), ya que en base a ellas no solo se valoraba una mujer a sí misma, sino que también era juzgada por su marido, sus vecinos y por la propia sociedad, en la que no había modo de alcanzar una posición si no se hacía gala de ellas. Sin ellas, de hecho, todo quedaba reducido "a cenizas", mientras que, con ellas, se tenía asegurada la felicidad e incluso el poder:

The attributes of True Womanhood, by which a woman judged herself and was judged by her husband, her neighbors and society could be dividid into four cardinals virtues - piety, purity, submissiveness and domesticity. Put them all together and they spelled mother, daughter, sister, wife -woman. Without them, no matter whether there was fame, achievement or wealth, all was ashes. With them she was promised hapiness and power ${ }^{5}(152)$.

\section{Por Queen Victoria: la True Woman del modelo anglosajón}

En este encorsetado contexto, la crónica de sociedad vivió una etapa de esplendor durante el reinado de Victoria de Inglaterra (1837-1901), que se extendió a lo largo de la mayor parte del siglo XIX. No obstante, ya ostentó bastante protagonismo con anterioridad, durante el periodo inglés de Regencia, en las primeras décadas de la centuria. Además de por sus colonias, la era victoriana expandió su influjo por

\footnotetext{
${ }^{4}$ Así lo recoge la autora, aludiendo, por ejemplo, a las Letters to Young Ladies, de Mrs. L. H. Sigourney (1835), en las que se ofrece a las jóvenes consejos para desenvolverse correctamente en sociedad según los convencionalismos establecidos, algo que se convierte en todo un clásico en el momento, y a Life at the Fireside (1857), de W. Thayer, en la nota 74 de la página. Este aspecto central de la cultura de la mujer verdadera ha sido extensamente analizado desde el ámbito académico, dando incluso nombre a estudios como The Light of the Home (2003), de Harvey Green, publicado inicialmente en 1983.

5 "Los atributos de la Verdadera Mujer, por los cuales una mujer se juzgaba a sí misma y era juzgada por su esposo, sus vecinos y la sociedad podían dividirse en cuatro virtudes cardinales: piedad, pureza, sumisión y domesticidad. Pónganlos todos juntos y deletreaban madre, hija, hermana, esposa: mujer. Sin ellos, no importaba si había fama, logros o riqueza, todo eran cenizas. Con ellos se le prometía felicidad y poder" (esta y otras traducciones son propias).
} 
Norteamérica y buena parte de Europa, y las revistas para mujeres, como las norteamericanas Godey's Lady's Book (1830-1878), también conocida como Godey's Magazine and Lady's Book, y la que nació para ser su competidora, Peterson's Magazine (1842-1898), se erigieron, en general, como las más relevantes promotoras de la cultura de la domesticidad y del culto a la verdadera feminidad, exponiendo en sus páginas directrices de moda (la mujer debía mantenerse a la última para complacer a su marido), indicaciones para la decoración y cuidado del hogar, sin olvidar, naturalmente, los consejos para que toda mujer se transformara en reflejo de las cuatro virtudes cardinales. Surgida más de una década después de Godey's, Peterson's Magazine, con Ann S. Stephens al frente de la cabecera como editora, llegó a superar en éxito a la primera, aunque esta ya se había convertido en todo un emblema. Conforme a los convencionalismos establecidos, Peterson's presentaba al público femenino como modelo a imitar a Martha Washington o publicaba entre sus exitosas páginas poemas como "The Star of my Home"6. Por su parte, Godey's Magazine and Lady's Book exaltaba en composiciones como "Female Charms" el valor de la pureza y la sumisión, siendo esta, como una imposición divina, la virtud más esperada en la mujer: "Submission was perhaps the most feminine virtue expected for woman (...) but men were the movers, the doers, the actors. Women were the passive, submissive responders. The order of dialogue was, of course, fixed in Heaven" 7 (Welter, 1966: 158). Asimismo, la domesticidad se resaltaba como uno de los dones femeninos más preciados, como expone Welter, en otros textos de Godey's, supuestamente humorísticos: "A Tender Wife" o "MY WIFE! A Whisper", en los que se aseguraba que algunas mujeres solo eran felices si sus maridos enfermaban para poder cuidarlos y sentirse útiles (164).

Sin embargo, al frente de Godey's también estaba una mujer, Sarah Josepha Hale, y, a pesar de la línea editorial de la revista y aun dentro de este concepto de esfera de la mujer (women's sphere), su afán por mejorar la educación femenina la convirtió en una de las editoras de prensa más relevantes de su tiempo. No en vano en 1846 llegó a afirmar a través de las páginas de la publicación que "el mayor triunfo" era la "progresión" y que, por tanto, había que "redimir a la mujer de su posición inferior y colocarla al lado del hombre", aunque, eso sí, como "ayuda para él en todas sus actividades": "The greatest triumph of this progression is redeeming woman from her inferior position and placing her side by side with man, a help-mate for him in all his pursuits" $^{8}$ (Merrill, 1975: 298).

\footnotetext{
${ }^{6}$ Peterson's Magazine, vol. 18, no 1, julio de 1850, pp. 17-19.

7 "La sumisión era quizá la virtud más femenina que se esperaba de la mujer (...) pero los hombres eran los motores, los hacedores, los actores. Las mujeres eran las respondedoras pasivas, sumisas. El orden del diálogo era, por supuesto, fijado en el Cielo".

8 "El mayor triunfo de esta progresión es redimir a la mujer de su posición inferior y colocarla al lado del hombre, una ayuda para él en todas sus actividades".
} 
Otras revistas, también estadounidenses, especialmente populares en las décadas de los 70 y 80 del siglo XIX, como Harper's y Frank Leslie's Illustrated, ayudaron a dispersar los valores de la clase media por todo el país (Fitts, 1999: 45). Una de las más destacadas cabeceras surgidas en estos momentos fue Good Housekeeping que, como la polifacética Harper's (New Monthly Magazine, de 1850) y Harper's Bazaar (1867), dedicada a la moda y estilo de vida, ha conseguido sobrevivir al paso del tiempo actualizando sus contenidos. Surgida en 1885 en Estados Unidos, en 1922 su éxito se complementó con el nacimiento de su edición británica, siguiendo la misma línea editorial de la revista femenina original, centrada en la economía del hogar. Más allá de las típicas recetas de cocina o los consejos para ser la perfecta esposa y ama de casa, incluía también, como ya hicieran Godey's Lady's Book, Peterson's Magazine o Harper's, todo un repertorio de instrucciones en relación con el protocolo de normas sociales relativas, por ejemplo, a los buenos modales en la mesa (Green, 2003: 47-48).

Ante esta situación, no es de extrañar que las revistas que se dedicaban a tratar este tipo de temas y a perpetuar el establishment gozaran de bastante más aceptación que las que ofrecían una visión femenina alternativa, de corte feminista. Sin embargo, este pensamiento pronto comenzó a calar con fuerza entre las lectoras. Endres y Lueck (1995: XII) destacan el caso de Lady's Emporium, editada por Mary Barney, cuya corta vida (solo un año) se debió, más que probablemente, a su avanzado carácter progresista, mientras que las publicaciones adscritas al culto a la verdadera feminidad se mantuvieron (y se mantienen aún en notables ejemplos, como hemos visto) durante generaciones. No obstante, la perfección de la verdadera mujer, del ángel del hogar, llevaba consigo la semilla de su propia destrucción: si las mujeres eran poco menos que los ángeles, sería lógico que tuvieran un papel más activo en la Creación, sobre todo teniendo en cuenta que, históricamente, los hombres tampoco lo habían hecho especialmente bien. De ahí que la True Woman acabara diendo paso a la moderna y bastante más liberal New Woman (Welter, 1966: 174), con todo lo que ello implicaría en la sociedad, en general, pero también en el ámbito de la prensa, en particular.

Pero volvamos al caso de la pionera Godey's, como muestra de la influencia de los convencionalismos ingleses en el contexto americano, pero también de la importancia que la publicación tuvo en el éxito de la crónica de sociedad escrita por mujeres, tema que fundalmentalmente nos atañe. La revista, aunque estadounidense, adoptó por influencia de Sarah J. Hale a la reina Victoria como modelo de feminidad y moralidad (Endres y Lueck, 1995: 115), e incluso se encargó, por el firme convencimiento de su editora, a la conocida Mrs. Sigourney (Lydia Howard Huntley) que informara como corresponsal en Londres sobre las actividades de la realeza (Blum, 1985; Potvin, 2009: 44), lo que brindaba ya grandes posibilidades a la crónica de sociedad, eso sí en una versión un tanto convencional, y acentuaba aún más el gusto del público norteamericano por lo inglés. De hecho, ello supuso el despegue del éxito de un género que informaba no solo de la vida pública de las altas esferas, sino también de una imagen 
más cotidiana y, a ser posible, con todo lujo de detalles, destacando aspectos de moda, costumbres o cuestiones más personales. La obra de Mrs. L. H. Sigourney en Godey's desempeñó un papel esencial en este sentido, resaltando esa conexión entre vida privada y pública de miembros de la realeza inglesa, pero también de personalidades de otras, como la española. Así hizo con la reina María Cristina de Borbón-Dos Sicilias, viuda de Fernando VII y madre de Isabel II, con la huella que esto dejaría además en la prensa española. Sigourney se valió de su poema "Queen Maria Christine's Farewell" 9 ("Despedida de la reina María Cristina”) para plasmar su peculiar visión de su exilio en 1840, mostrándola en su doble faceta de madre y reina, con lo que reforzaba el poder de esta ante los lectores al situarles en la propia piel de la que hasta entonces había sido regente debido a la minoría de edad de su hija Isabel (Okker, 1993: 39).

Además de la gran aceptación del público, en el éxito de la crónica de sociedad sería determinante tanto el buen hacer periodístico, como el de sus propios protagonistas. En este sentido, no es de extrañar que la reina Victoria supiera aprovechar el potencial mediático de la fotografía, que pronto la convirtió en un símbolo en Inglaterra, América y las colonias. Su ejemplo sirvió de inspiración en España a Isabel II, gran admiradora de Victoria, que encargó un retrato de esta al fotógrafo británico Charles Clifford y que también se dejó retratar por el mismo según el estilo inglés (Potvin, 2009: 44-45). Clifford, asimismo, dejó constancia fotográfica de los viajes oficiales de Isabel por tierras españolas a través de su obra, en lo que sin duda constituye toda una muestra icónica de la crónica de sociedad, utilizada además con un evidente valor propagandístico de carácter político.

Y es que desde su juventud la reina Victoria había logrado despertar auténtica fascinación dentro y fuera de las fronteras inglesas. Como consecuencia de este fenómeno, Godey's y Hale, que también fue la artífice de la celebración del Día de Acción de Gracias, introdujeron en América, y posteriormente en el resto del mundo, la tradición del árbol de Navidad (publicando en 1850 un grabado en el que se mostraba una adaptación de una imagen de la familia real inglesa, a una familia media norteamericana en torno al árbol) ${ }^{10}$ y del vestido blanco (color elegido por Victoria, frente a la costumbre entonces usual de los tonos coloridos, en su boda con el príncipe Alberto diez años antes) para las novias, lo que la revista asoció a la pureza virginal ${ }^{11}$. La

\footnotetext{
${ }^{9}$ Godey's Lady's Book, vol. 22, enero-junio de 1841, p. 206.

${ }^{10}$ La revista publicó la imagen, que popularizó en pocos años en Norteamérica la importación de la costumbre europea del árbol de Navidad, en su número de diciembre de 1850, a partir de un grabado de la reina Victoria y su familia en el Castillo de Windsor alrededor de un árbol especialmente decorado para la ocasión, publicado dos años antes en The Illustrated London News (Marling, 2001: 164-165).

${ }^{11}$ En su edición de agosto de 1849 (vol. 38), Godey's resaltaba en su sección "Protocolo de ajuar" (“Etiquette of Trousseau”) y en el artículo “The Bride's Dress!" (“iEl vestido de novia!") la importancia de la elección del color blanco para el enlace matrimonial, como "emblema" del "corazón inmaculado" que se "cede al elegido": "It is an emblem of (...) the unsullied heart she now yields to the chosen one" ( $p$.
} 
relevancia del calado de la vida de la royalty en las costumbres de la población evidenciaba que, definitivamente, la crónica de sociedad había triunfado. Y no solo en el mundo anglosajón. Ya hemos referido algunos ejemplos de la influencia que la información acerca de las actividades de la realeza británica o de la propia realeza española por parte de la prensa norteamericana ejerció en España, donde el modelo femenino de ángel del hogar también ejercía su preponderancia aunque, como en el caso anglosajón, comenzaran a resultar significativas notables excepciones en la cultura popular decimonónica. Pero la crónica de sociedad se erigía como un género periodístico difícil de superar a la hora de plasmar los fundamentos de un modo de vida que reflejaba los cánones de apariencia femenina dictados por el modelo patriarcal de la época, aunque también podía criticarlo; un género que empezó a hacerse un hueco cada vez más importante en las páginas de la prensa española y en el que pronto comenzaron a sobresalir los textos de autoría femenina.

\section{Lady Whistledown y Mrs. Crackenthorpe}

Aunque con gran popularidad en la época victoriana, la crónica de sociedad (pero más en su amplio abanico de curiosidades, anécdotas o cotilleos sobre las altas esferas) ya había tenido, desde el siglo XVIII, una muy buena acogida en etapas anteriores, como el periodo inglés de Regencia, que estrictamente se enmarca entre 1811 y 1820 (cuando el rey Jorge III fue declarado no apto para gobernar y le sustituyó como príncipe regente su hijo Jorge IV), aunque más ampliamente se extiende entre 1795 y 1837, marcando el tránsito del siglo XVIII al XIX y prolongándose a lo largo de sus casi cuatro primeras décadas como un periodo de transición entre las épocas georgiana y victoriana. En este periodo se ambienta la ya popular serie de televisión Los Bridgerton (The Bridgerton Chronicle), basada en las novelas de la escritora estadounidense Julia Quinn y que narra las historias de los ocho hijos de una familia de la clase alta londinense, mostrando los entresijos del complejo entramado del protocolo social existente. El rápido éxito de la serie, producida por la plataforma Netflix y emitida en su primera temporada el 25 de diciembre de 2020 como producción estelar de la compañía para las fiestas navideñas, vino acompañado de la polémica surgida sobre su discutida fidelidad histórica (habría que diferenciar aquí entre ficción "histórica" y "de época"12), debido a las peculiares licencias que se permite el guión.

156). La elección de la reina Victoria (y los comentarios en la prensa sobre esta decisión) motivó que el color blanco se pusiera rápidamente de moda entre las jóvenes para el día de su boda.

${ }^{12}$ Aunque partimos de la base de que toda ficción es en sí misma un relato imaginario, la "ficción histórica" se entiende como el recurso de evocación de "un pasaje de la Historia" o de "personajes históricos, con el fin de narrar acontecimientos del pasado aunque su enfoque histórico no sea riguroso", con lo que se 
En el caso de Los Bridgerton, a pesar de su ambientación en la época de Regencia y de contar en su guión con personajes reales como la reina Carlota o el rey Jorge III, se ofrece, por ejemplo, una visión de integración de la población de origen africano en la nobleza inglesa que poco tiene que ver con la realidad del momento. Esta interpretación surge a raíz de la imagen de Carlota (de Mecklemburgo-Strelitz), que se muestra en la serie como desdecendiente directa de una rama africana de la familia real portuguesa, según una controvertida versión histórica que se apoyaría, entre otras supuestas pruebas, en retratos de la reina realizados por el escocés Allan Ramsay, una versión que defienden historiadores como Mario de Valdes y Cocom, especializado en la diáspora africana (Gregory, 2016: XIV-XV), y Bethany Rebekah Holt Gregory, al referirse a la consorte del rey Jorge III de Inglaterra como "the first African queen" (2016: III). La serie, además, se permite otras licencias, como adaptar temas de música de hoy en día al estilo del periodo de Regencia y abordar los contenidos emocionales de una forma muy actual.

Independientemente de las controversias sobre el rigor histórico, lo cierto es que el éxito de la trama se debe en gran medida al hecho de ser mostrada a través de los epistolares society papers de Lady Whistledown, personaje de ficción que no solo informa de actividades de la alta sociedad londinense, sino que también desvela sus más ocultos escándalos, lo que hace que la publicación periódica de sus papeles de sociedad sean esperados con vehemencia hasta por la propia reina que, a pesar de la curiosidad que en ella despiertan, intenta acabar con la publicación. Aunque se trata de un personaje de ficción, la enigmática Lady Whistledown (ya que su firma es un seudónimo) se basa en auténticos referentes históricos de la prensa inglesa. El caso más destacable es el de Mrs. (Phoebe) Crackenthorpe (seudónimo tras el cual estaría la polémica escritora Delarivier Manley, habitual en la prensa inglesa del momento, aunque, como en el caso del personaje de Los Bridgerton, mucho se ha discutido sobre su identidad ${ }^{13}$ ),

acerca más "al carácter novelado del relato". Cuando, además, encontramos "una voluntad directa" de evocar un determinado periodo o hecho histórico, "reconstituyéndolo con más o menos rigor, dentro de la visión subjetiva de cada realizador", asistimos a una clara intencionalidad de "hacer Historia" y entraríamos en lo que se puede denominar "reconstitución histórica" (Caparrós Lera, 2007: 33-34). Por su parte, con la expresión de ficción "de época” nos referiríamos a aquella ficción histórica que se permite ciertas licencias aún más extremas en relación con la concepción más rigurosa de la historiografía, de manera que el relato quedaría más alejado de la transcripción de la realidad. Es el caso de Los Bridgerton que, a pesar de su ambientación en el periodo de Regencia y de incluir en su trama a personajes históricos de la realeza inglesa o prusiana de la época, se extralimita un tanto en cuanto al concepto del rigor histórico se refiere.

${ }^{13}$ Estudios pioneros como el de Paul Bunyan Anderson (1931) aluden a Delarivier Manley (Mrs. Mary de la Riviere Manley) como la autora que se halla "tras la máscara", según las propias palabras de la polémica escritora en la presentación de su influyente sátira política sobre los derechos de la mujer The New Atlantis (Secret Memoirs and Manners of Several Persons of Quality, of both Sexes, From The New Atalantis), en irónica alusión a la utopía altruista de Francis Bacon New Atlantis (1627): "Mrs. Manley shows herself beneath the masque of Mrs. Crackenthorpe in introducing material from the New Atlantis" (359). A pesar de posteriores discrepancias académicas, ya que también hay quienes han negado la autoría a la escritora inglesa y señalado que sería un hombre (el dramaturgo Thomas Baker) quien se escondería tras el seudónimo de Mrs. Crackenthorpe (Graham, 1937), Anderson concluía rotundamente en su artículo "Mrs. Manley is Mrs. Crackenthorpe" (360). Asimismo, otro elemento a tener en cuenta en 
columnista de principios del siglo XVIII especializada en tratar los ecos de sociedad con un tono satírico-político, en textos que recogía desde La Chismosa revista londinense The Female Tatler (1709-1710).

En esta publicación, que surge como respuesta a The Tatler (1709-1711), de Richard Steele, Mrs. Crackenthorpe (A Lady that knows every thing ${ }^{14}$ ), cuyo seudónimo fue sustituido posteriormente por el de una Society of Modest Ladies (en la que también podría haber participado Delarivier Manley) ${ }^{15}$, aireaba las informaciones poco discretas, concebidas como herramientas de vigilancia social, relativas a los miembros de las altas esferas. Mucho se ha escrito igualmente sobre quién estaba detrás de esta última firma, apuntándose a Bernard Mandeville (Anderson, 1936; Goldsmith, 1999). El estilo de los textos de la misteriosa Society of Ladies (con escritos de Emilia-Rosella, Lucinda, Artesia, Arabella y Sophronia) contendría numerosos elementos coincidentes con los presentes en la obra más famosa de Mandeville, filósofo y escritor satírico holandés pero afincado en Inglaterra, y autor de The Fable of the Bees (La fábula de las abejas), publicada en 1714 y en la que se ponen de manifiesto Private Vices, Public Benefits (Vicios privados, beneficios públicos). En cualquier caso, independientemente de quien se escondiera detrás de la atrevida firma, resulta esencial el hecho de que The Female Tatler y su Mrs. Crackenthorpe crearan en la sociedad del momento un influyente pensamiento de asociación entre la figura de la mujer y su papel como autora de una crónica más orientada hacia una perspectiva política-moralista, ya en los albores del siglo XVIII.

\section{Del moralismo de Beatriz Cienfuegos a la moda en las pioneras españolas del XIX}

Pero, ¿qué sucedía mientras tanto en España? En la segunda mitad del mismo siglo XVIII y también en esa misma línea de observadora moral de la sociedad, encontramos a $L a$ Pensadora Gaditana (1763-1764, en una primera etapa, resurgiendo como libro en

\footnotetext{
la amplia discusión sobre la autoría de la revista sería la publicación de algunos números de The Female Tatler por un editor diferente al original con una supuesta suplantación de Mrs. Crackenthorpe (Smith, 1952).

${ }^{14}$ Obsérvese el paralelismo entre Mrs. Crackenthorpe (como Una Dama que lo sabe todo) y el personaje de Lady Whistledown, igualmente presente en la imagen del rostro de una dama de la época que se reproduce en la cabecera de The Female Tatler y, de forma muy similar aunque bastante más velada, en los society papers de Lady Whistledown.

${ }^{15}$ Autores como Goldsmith (1999: 43) hablan de esta posibilidad, no menos discutida que la identidad de Lady Whistledown.
} 
1786), obra editada en Cádiz (como su propio nombre indica, pero también en Madrid) de la mano de la igualmente enigmática y no menos polémica Beatriz Cienfuegos. Mucho se ha escrito también acerca de la identidad de quien estaba tras esta firma. En este sentido, llama la atención la aparente paradoja creada por la supuesta autora de la publicación en los propios textos de su semanario. Y más aún cuando, como sucede con The Female Tatler, a través de sus artículos o "pensamientos" femeninos se enfrenta a una ferviente dialéctica con otra publicación de crítica moral, El Pensador (1762-1763 y con una segunda época en 1767) de José Clavijo y Fajardo, periódico editado en Madrid que centra sus diatribas en tipos sociales o en estamentos como la nobleza, incluso en la monarquía, pero no en particulares y siempre con un estilo sutil, sin traspasar los límites de la legalidad vigente. La Pensadora acusa a El Pensador de infravalorar a la mujer y lamenta que haya quienes crean que una mujer no puede expresar sus pensamientos como un hombre, refutándole la autoría de su publicación. Por ello, en su periódico, Cienfuegos no duda en confirmar que es una mujer (“Pensamiento III"):

porque todos porfían, y a su parecer con razón, de que no es Mujer la Pensadora: ¡Hay tal ignorancia! ¿Dios ha dado a las Mujeres otra Alma distinta, y de menos facultades que la de los Hombres? ¿O procuran hacer valer aquella antigua, y errada opinión, de que las Mujeres eran animales imperfectos, extendiéndola también a sus luces, a sus discursos y a sus entendimientos? (...) Desengáñense Vms. Mujer soy, y Mujer que tal cual sé discurrir: y ojalá que me fuera posible dejar de serlo, para de este modo alejarme cuanto pudiera de un Sexo, que tan poco procura su esplendor. ${ }^{16}$

Sin embargo, todavía en los últimos años se ha continuado especulando con una posible autoría masculina ${ }^{17}$, entre otros motivos, porque es la propia Cienfuegos la que, dentro de la dinámica artificiosa que emplea en sus escritos, a veces muestra una contradictoria actitud ambigua sobre su identidad. No obstante, bastante lógico resulta, en relación con este debate, estimar que, ante la ausencia de pruebas contundentes al respecto, se considere que Beatriz Cienfuegos (al margen de si este nombre es verdadero o ficticio,

\footnotetext{
${ }^{16}$ La Pensadora Gaditana, vol. 1, 1763, Pensamiento III, pp. 68-71. (En este y demás fragmentos reproducidos de publicaciones periódicas o de libros antiguos hemos actualizado la ortografía, aunque respetando, en este caso, la intención de la autora de destacar algunas palabras con el uso de mayúsculas).

${ }^{17}$ Ante esta cuestión se ha planteado una gran diversidad de argumentos al respecto. Resulta bastante ilustrativa la edición antológica llevada a cabo por Cinta Canterla González de los textos de Beatriz Cienfuegos en La Pensadora Gaditana (1996: 21-25), así como lo referido en otra publicación de Canterla González (1999), "El problema de la autoría de La Pensadora Gaditana" (29-54). También resulta interesante lo que señala Sánchez Hita (2009: 222-225), además de Sullivan (1995: 27-47) y FernándezQuintanilla (1981: 139), entre otros, antes de llegar a determinantes investigaciones más recientes (Canterla: 2018).
} 
porque también hay argumentos que defienden la veracidad del mismo) fue, realmente, una mujer:

sugerí en mi introducción aplicarle a La Pensadora la misma convención a la que se ha llegado en otras disciplinas en casos similares en los que se había dudado de la autoría femenina de un texto: si el estado de la cuestión no permite llegar a conclusiones definitivas, dar el nombre provisionalmente por válido, para no incurrir en la falta de rigor consistente en dar crédito a argumentos sin ninguna fuerza (que sería, quiérase o no, la otra cara de la moneda) y exigiendo nuevas vías de investigación a la cuestión de la autoría. No se comprende que alguien se escandalice porque se proponga dar el nombre de la autora provisionalmente (y problemáticamente) por válido, y no por dudar de él y negarlos, cuando esto último está aún menos documentado que lo primero (Canterla González, 1999: 42).

Ante esta situación, investigaciones más recientes llevadas a cabo por esta misma autora pondrían fin a la polémica, al concluir que tras el seudónimo de Beatriz Cienfuegos se escondería Beatriz Manrique de Lara Alberro, Marquesa de García del Postigo. El seudónimo estaría compuesto por su propio nombre y un anagrama a partir del nombre de su hija, ya que las letras de Cienfuegos "están en el nombre y apellidos de Francisca, que en la versión abreviada del apellido de sus padres era Francisca del Postigo Manrique, y en la extensa, Francisca de Paula García del Postigo y Manrique de Lara" (Canterla, 2018: 744).

Dejando a un lado la cuestión de la autoría, en una línea moralista similar a la de la publicación de Mrs. Crackenthorpe, La Pensadora Gaditana muestra, y también critica, a través de sus "pensamientos" la difícil realidad sociopolítica de la época (en este caso de una España, en pleno reinado del reformismo ilustrado de Carlos III, de transición del Antiguo al Nuevo Régimen) y de las mujeres de su tiempo, cuyos vicios también censura desde una óptica bastante avanzada. Presenta así "una metáfora o fábula del enfrentamiento de la España antigua que muere y la nueva España liberal que comienza a nacer", lo que expresa a través de la simbología del "recurrente tema" de la "falta de entendimiento mutuo entre los castellanos antiguos de la España del interior", y el "irreverente, desacralizador (de la monarquía, de la institución religiosa, del sentido calderoniano del honor) y sensual sentido de la vida de los gaditanos", en el que las "distancias (no sólo entre hombres y mujeres sino entre distintas clases sociales, nacionalidades, confesiones, etc.) se diluyen". Una dicotomía que manifiesta además a la hora de plasmar las "diferencias existentes" entre la "educación moderna" de la mujer del sur, acorde con su mentalidad, y "la severidad, coerción, puritanismo y atraso de las españolas "castellanas antiguas'" (Canterla González, 1999: 37-45). Los textos de Cienfuegos, de este modo, van más allá de la crónica que se limita a informar de las actividades de la alta sociedad con la intención de mantener el orden establecido y se 
adentran, como ocurre en The Female Tatler, en una actitud de vigilancia con respecto a las costumbres, que no duda en alcanzar a las más altas esferas del poder político y religioso del momento.

Asimismo, los escritos de La Pensadora se nutren de una notoria tradición de prensa moral, que critica a la sociedad pero, como hemos visto también en el caso de su rival EI Pensador (que denuncia las modas de la época, la coquetería, la frivolidad femenina, la costumbre del cortejo o las imitaciones de comportamientos entre plebeyos y clases altas), sin centrarse en el quién sino más bien en las instituciones, con notables influencias importadas de diversas publicaciones inglesas, además de The Female Tatler: The Spectator (1711-1712 y 1714), de Joseph Addison (también hubo The Female Spectator, publicado entre 1744 y 1746 por Eliza Haywood, con sus interesantes críticas a la "adicción" femenina "al juego y los excesos del té"18), y por supuesto, el ya señalado The Tatler de Richard Steele (que es también artífice con Addison de The Spectator), además de otros Espectadores. En ellos, los redactores suelen presentarse también como murmuradores y observadores, más o menos invisibles recurriendo habitualmente a los seudónimos o directamente al anonimato, guiados por una pasión analítica y censora para reprobar lacras y vicios sociales. Una tradición en la que resulta especialmente relevante, como precedente aunque clandestino, el que se erigirá en importante referente para los Duendes (que le imitarán) y otros periódicos que desempeñarán con posterioridad un papel fundamental en el ámbito de la prensa de crítica política-satírica española decimonónica.

Hablamos del Duende Crítico, Duende Político de Palacio o Duende de Madrid, manuscrito, de la primera mitad del XVIII español (1735-1736), y en el que sí se considera más que importante referirse con claridad a quienes se critica: desde la propia reina a las más altas élites de la corte, siguiendo a su vez la tradición barroca del libelo anónimo (Egido López, 2002). La reina Isabel de Farnesio (segunda esposa de Felipe V) y José Patiño, ministro plenipotenciario del primer monarca español de la dinastía borbónica, se convierten, de hecho, en los principales blancos de sus invectivas en verso, además del propio rey, sin dejar atrás sus atrevidas alusiones a la ignorancia de los legisladores o a la hipocresía de la corte. Aunque el autor (el portugués Manuel Freyre da Silva o fray Manuel de San José) se ocultaba tras la máscara periodística, fue finalmente descubierto y encarcelado, quedando pues suspendido este periódico clandestino que inaugurara la prensa satírica en España. Al margen de la clandestinidad, el primero de los periódicos morales en España fue El Duende Especulativo sobre la Vida Civil (aparecido en 1761) del holandés Juan Enrique Graef, oculto tras el seudónimo de Juan Antonio Mercadal (Sánchez Hita, 2009: 220).

\footnotetext{
${ }^{18}$ Así lo recoge Spacks (1999: 15) dentro de la selección de artículos que publica de la revista inglesa.
} 
Con la llegada del siglo XIX, se impusieron nuevas fórmulas y, como también hemos visto en el caso de la prensa inglesa de la época, la crónica de la alta sociedad, de corte más informativo pero también halagador, en la que se detallaban las actividades de la realeza y otras altas esferas, suscitó el interés de las lectoras (y de no pocos lectores) de prensa. Las autoras pioneras de la prensa española del momento, en un periodo de tránsito del tradicionalismo al progresismo, recurrieron a la crónica de sociedad como género periodístico estelar en la prensa ilustrada. Autoras como Emilia Serrano de Tornel (Baronesa Wilson) se sirvieron además de la descripción costumbrista de fiestas y modas para ir más allá y criticar la situación de la mujer en la época (Fernández-Ulloa, 2018; Fernández Ulloa y Benítez Alonso, 2019). En La Caprichosa (editada en París entre 1857 y 1860, pero de amplia difusión entre el público español), por ejemplo, que funda y dirige, describirá y comentará la moda parisina que se exhibe en salones y teatros, aludiendo, especialmente, a quienes integraban la colonia española en París, detallando de forma exhaustiva todo tipo de prendas, no solo vestidos, sino también corpiños, anaguas, manteletas o sombreros. Más interesantes resultan para nuestro análisis sus crónicas de las altas esferas, referidas al matrimonio de la princesa en Inglaterra o a un viaje de los príncipes de Prusia ${ }^{19}$, así como los textos de contenido moral en línea con los precedentes periodísticos vistos en el siglo XVIII. En este sentido, se vale de la narración de relatos que, según señala, le son referidos, para prevenir sobre los celos (“Las apariencias engañan") y otros peligros en el matrimonio, ${ }^{20}$ fórmula que repetirá en El Mundo Pintoresco (1858-1860). ${ }^{21}$

Pero la moda establecerá en estos momentos una relación un tanto simbiótica con la crónica de sociedad, hasta el punto de que no solo autoras, entre las que también podemos incluir a Emilia Pardo Bazán, sino incluso escritores (y de no menos renombre, como el propio Bécquer) serán partícipes de esta poderosa alianza en la prensa española decimonónica, especialmente visible entre las revistas consideradas femeninas, destinadas, principalmente pero no exclusivamente como ya hemos referido, a la mujer:

basta leer las crónicas de sociedad publicadas en El Contemporáneo, en 7 y 8 de febrero de 1864: "Revista de salones" y "Bailes y bailes". Su descripción de los trajes y tocados de las damas asistentes, son dignas del mejor comentarista de modas, sin que falte, además, en ellas, algún rasgo que revela al poeta. Pero lo más importante es que al final del segundo texto, manifiesta el entusiasmo con que ejerce esa tarea de describir "un mundo encantador" (...) "de tules, gasas y aderezos y coronas de flores..." (Palomo Vázquez, 2014).

\footnotetext{
${ }^{19}$ En los números de febrero de 1858 (p. 8) y marzo de 1858 (p. 10) de La Caprichosa, respectivamente.

${ }^{20}$ La Caprichosa, marzo de 1858, pp. 5-9.

${ }^{21}$ El Mundo Pintoresco, vol. 3, no 6, 5 de febrero de 1860, pp. 42-43.
} 
Lejos de ser un género anclado en el pasado, la crónica de sociedad redactada por mujeres, por otra parte, supo evolucionar asimismo con las ideologías de los nuevos tiempos. De hecho, la revista Ellas (1851-1853), que nace con "el tono reivindicativo de una proclama liberal exaltada" y que se "lamenta del yugo a que el hombre somete a la mujer" (Jiménez Morell, 1992: 82), aunque posteriormente retorna a un espíritu más conservador, publica una crónica firmada por Salomé Abellá, corresponsal de la revista en París, en la que comenta que el bloomerismo (movimiento norteamericano a favor de la reforma de la tradicional indumentaria femenina, y que abogaba por que la mujer usara pantalones y levita) había llegado a la capital francesa (88).

\section{De la Condesa de Merlin y la Bassanville a Fernán Caballero, alta sociedad en la prensa sevillana}

En su doble vertiente, la más próxima a la crítica social característica de la prensa moral del XVIII o la más informativa, pero también conservadora, referente a las actividades y gustos de las altas esferas, la crónica de sociedad de autoría femenina desempeñó igualmente un relevante papel en la prensa sevillana del siglo XIX aunque, como ya resaltábamos al inicio de este trabajo, este campo está prácticamente inexplorado. En él hallamos, no obstante, notorias firmas como la de Fernán Caballero (conocido seudónimo, especialmente desde el ámbito literario, de la autora hispano suiza Cecilia Böhl de Faber) o la de una hoy mucho menos conocida, pero bastante interesante, Condesa de Bassanville (seudónimo, al igual que el de Anaïs de Bassanville, de la escritora francesa Thérèse Anaïs Rigo). Pero también encontramos la firma de otra singular escritora, hispano cubana, la Condesa de Merlin (María de las Mercedes Santa Cruz y Montalvo), además de las de otras autoras que escriben, con carácter anónimo, crónicas de moda de la alta sociedad, especialmente. Sus textos destacan, principalmente, en dos cabeceras emblemáticas de la prensa sevillana decimonónica. Por un lado, en la Revista de Ciencias, Literatura y Artes (1855-1860), publicada durante el reinado de Isabel II y que Chaves Rey, en su ya clásica Historia y bibliografía de la prensa sevillana (editada inicialmente en 1896), define como una "notable revista", que contó con "celebrados autores" (entre ellos algunas de las autoras pioneras en la prensa sevillana deI XIX, como Antonia Díaz y Ángela Grassi, además de otras de las ya citadas) y de la que "puede decirse que, por los trabajos que en ella aparecieron, fue de las mejores que se han publicado en Sevilla" (1995: 138). Por otro, y en bastante menor medida, en la más antigua Revista Andaluza (1841), a la que Chaves Rey se refiere como "curiosa y bien escrita publicación", con "muchos trabajos de mérito" y de lectura “interesante" (1995: 92). 
El primero de los textos que encontramos en la Revista Andaluza pertenece a la Condesa de Merlin (título real que añade en la firma de sus escritos de forma habitual por su matrimonio con el general bonapartista y conde Antoine Christophe) y lleva por título "Los esclavos en las colonias españolas". Mercedes Santa Cruz (1789-1852), nacida en La Habana aún española, es considerada fundadora de la literatura cubana de autoría femenina y pionera en la crónica de sociedad. En ello ejerció una influencia decisiva su condición de aristócrata, no solo por su matrimonio, sino también por su nacimiento, ya que los Santa Cruz eran condes de Santa Cruz de Mopox y de San Juan de Jaruco; los Montalvo, de Macuriges y de Casa Montalvo. De hecho, su privilegiada posición le permitió conocer de cerca la vida de la corte española, tras su viaje de niña a Madrid para reunirse con su madre, dama de honor de la reina María Luisa de Parma. Asimismo, tras la invasión napoleónica, su familia acuerda su boda con el general erigido conde de Merlin por José I. Al ser derrocado el rey Bonaparte en España, se ve obligada a exiliarse con su esposo en París, pues la condesa también había tenido una relación muy próxima a José Bonaparte a través de su tío materno, el afrancesado general O’Farrill, e incluso se habla de una supuesta relación amorosa entre José I y la madre de Mercedes. Allí la Comtesse Madame de Merlin fue testigo y protagonista, causando sensación con su personalidad criolla, de los últimos brillos del imperio de Napoleón (Ezama Gil, 2009: 464-465).

"Los esclavos en las colonias españolas", artículo que la Revista Andaluza recoge en 1841 de la Revue des Deux Mondes ${ }^{22}$ y traduce del francés (lengua en la que habitualmente escribía la Condesa de Merlin), presenta rasgos de la crónica que censura determinados aspectos de la sociedad del momento, adentrándose además en el terreno de lo político. Pero el texto muestra una actitud no demasiado crítica de la autora, debido a su doble condición cubano-española, frente a la esclavitud. No manifiesta un posicionamiento abolicionista (aunque sí contrario al tráfico de los esclavos), ya que rechaza que exista un tratamiento inhumano por parte de los criollos y advierte de que "la armonía mágica de la palabra libertad engaña y alucina a muchos espíritus" (1841: 241), aprovechando además para culpar a los ingleses de fomentar la leyenda negra contra España con falsa filantropía proselitista (243-245) y lucrativa (254), y de poseer, junto con los franceses, una legislación mucho más "dura y severa" que la de los españoles (278). Su extensa argumentación, en la que recurre además al transcurrir histórico sobre el asunto, no está exenta de racismo, al asegurar, en alusión a la mezcla de razas, que "la naturaleza ha rubricado con su mano la incompatibilidad" de las mismas (249) y señalar que, aunque los esclavos consigan estar "emancipados" (condición previa a la libertad), no saben vivir de otra manera (253 y 276-277). O al asegurar que "no son nada fieles" y que "carecen de principios", por lo que los considera proclives al robo (276). Pero, entre sus controvertidas explicaciones, la condesa ofrece una minuciosa descripción de multitud

\footnotetext{
${ }^{22}$ Así se indica en nota a pie de página (241) de la Revista Andaluza, vol. 2, 1841. El artículo se publica en las páginas $241-255$ y $273-293$.
} 
de detalles de la vida cotidiana en los ingenios azucareros y plantaciones de la Cuba colonial, tanto en lo relativo a los esclavos como a los criollos, constituyendo un destacado exponente de la crónica de sociedad de las costumbres relacionadas con la esclavitud en la aún América española, aunque se manifieste una actitud de extremismo conservador, a favor del orden establecido. De este modo, al referirse a que los esclavos pueden comprar su libertad y que para este fin sus propios dueños "promueven y facilitan el rescate" de los mismos proporcionándole los medios de adquirir el dinero necesario, afirma:

Todo negro tiene permiso para criar en la casa gallinas y animales, que vende en el mercado para su provecho, así como legumbres, que cultiva con abundancia en su conuco o huertecillo. El dueño le concede este terreno que está contiguo al bojío, o choza que habita. El esclavo, después de haber concluido su tarea, se dedica los domingos y las noches a la luz de la luna a este cuidado, que se reduce en esta tierra de promisión a sembrar y recoger (274).

El discurso llega a ser especialmente duro cuando la autora se refiere a algunas de las costumbres del "código negro", del que reconoce su "monstruosidad" en relación con ciertos aspectos referentes a las normas de trato que rigen para los esclavos en la colonia. Estima como "disposiciones muy humanas y morales" el que se condene "al hombre libre, que tiene hijos de una negra, a una multa, y a la pérdida de la esclava y sus hijos, a menos que se case con ella" (275). O se justifica con la mayor dureza de las legislaciones inglesa y francesa, al asegurar:

Prohíben a sus esclavos el calzarse, y mientras que se ve tanto en sus colonias, como en las francesas, a aquellos desgraciados andar con los pies desnudos, y muchas veces ensangrentados, en tanto que aquellas esbeltas jóvenes con sus lucientes espaldas de color de cobre, adornadas de todos los encantos de la juventud, pero ruborizadas (tanto ilustra la misma ignorancia el instinto de la mujer) se atreven apenas a adelantar el breve pie fuera de su corta túnica, vemos a nuestras dichosas e indolentes chinas ${ }^{23}$ ostentar con coquetería a los rayos del sol en la extremidad de sus piernas de ébano un elegante zapato de raso blanco (278).

Pasando a otro modelo de crónica de sociedad, algunos años después, en 1855, y ya en la Revista de Ciencias Literatura y Artes, hallamos un texto firmado por la Condesa de Bassanville (seudónimo, al igual que el de Anaïs de Bassanville, de la escritora francesa Thérèse Anaïs Rigo, según ya señalamos) y titulado "La entrada en el gran mundo. Carta a mi sobrina"24. Hoy es prácticamente una desconocida, pero la Condesa de Bassanville (1803-1884) gozó de gran popularidad en su tiempo. De hecho, era considerada toda

\footnotetext{
${ }^{23}$ Se indica a pie de página que se llama así a "las hijas de negra y blanco".

${ }^{24}$ Revista de Ciencias, Literatura y Artes, vol. 1, 1855, pp. 47-51.
} 
una autoridad en lo que respecta al dominio de las buenas maneras y protocolo de las altas esferas, tema que centra este artículo, en el que recurre, algo usual en la autora y en otras de su época como hemos visto en este trabajo, al género epistolar dirigido a las jóvenes que se disponen a presentarse en sociedad (muy al estilo Bridgerton, por cierto), pero constituyendo, asimismo, una crónica de las costumbres de las altas esferas. Habitual en las revistas femeninas de su tiempo, comenzó a escribir utilizando el seudónimo de Comtesse de Bassanville, haciéndose pronto un hueco importante en el panorama periodístico del momento y fundando su propia revista, con el elocuente título de Journal des jeunes filles (Diario de chicas jóvenes). Fue además directora de Le moniteur des dames et des demoiselles (El instructor de las damas y señoritas) y de Le dimanche des familles (El domingo de las familias). La ficticia Condesa, en este sentido, llega a firmar crónicas ${ }^{25}$ en las que habla de las actividades que se desarrollan en los salones parisinos de la auténtica Condesa de Merlin, a la que llama L'Espagnole (Ezama Gil, 2009: 470).

"La entrada en el gran mundo" que la Condesa de Bassanville firma en la Revista de Ciencias, Literatura y Artes (y que esta cabecera recoge de una de las revistas que ella dirige, Le moniteur des dames et des demoiselles) ofrece todo un tratado, a modo de resumen, sobre lo que llama "buen tono" y la importancia de aprender las cualidades de "una educación esmerada" desde la juventud para evitar lo que les sucede a aquellas "mujeres, cuya afectación en el traje y en la manera de expresarse, no disfraza los vicios de su primera educación". Y añade:

Son recibidas en los salones más brillantes, en las casas más opulentas, y hasta en la sociedad de las señoras de mejor tono; porque sus inmensas fortunas o la posición social de sus maridos, les abren todas las puertas; pero a pesar de su riqueza, de su ruinosa elegancia o de los aires que quieren darse, están fuera de su centro en los círculos, donde son recibidas, por las ridiculeces o exageraciones en que incurren (1855: 47-48).

En este sentido, los consejos de la Condesa de Basanville para entrar en sociedad son pues buen reflejo de las costumbres de las altas esferas de la época, desde presentarse "con naturalidad, sin ningún género de afectación; porque la afectación desluce las cualidades más brillantes, en lugar de realzarlas", a ser "buena y amable" porque "la mujer hermosa agrada a la vista", pero mejor es "la mujer buena al corazón", por lo que, si "la primera es una joya; la segunda un tesoro" (48). Y continúa realzando cualidades que hay que cultivar y que constituyen grandes pilares del saber estar, y que siguen vigentes en nuestros días; valores como la modestia, la paciencia, la indulgencia, la

\footnotetext{
${ }^{25}$ La Condesa de Bassanville firma la crónica "Le salon de la Comtesse de Merlin", recogida en Les salons d'autrefois. Souvernirs intimes. Deuxième série, de la parisina Librería H. Aniéré, según señala Ezama Gil (2009: 470).
} 
autoexigencia (48-49). Por supuesto, habla también de los excesos de la moda y la extravagancia:

Leánse en tu persona y en los más insignificantes perfiles de tu traje, la más exquisita pulcritud. ¿Qué realce pueden dar las flores y los encajes a una toilette ajada o de mal gusto? La frescura y el corte airoso de un traje constituyen su primera elegancia; y te presentarás mucho mejor en sociedad con un sencillo vestido de tafetán, acabado de estrenar y de última moda, que con las telas más raras y costosas, si han perdido su primer brillo o son de anticuada hechura (49).

En sintonía, por otra parte, con el modelo de ángel del hogar, no es de extrañar que aconseje asimismo conservar "también en sociedad la costumbre de las labores de mano", porque estas ocupaciones "solo están desterradas de los grandes saraos, de los bailes, y de los conciertos: fuera de estos casos excepcionales, el dedal, las agujas y las tijeras deben acompañaros a todas partes, merced a que tales son, en cierto modo, los atributos de nuestro sexo" (50). La carta finaliza ironizando con "sus ribetes de sermón", pero que justifica sentenciando que "nada es más trascendental, que la entrada de una señorita en el gran mundo" (51).

Por último, recogemos las aportaciones de Fernán Caballero (Cecilia Böhl de Faber) a la crónica de sociedad, en su concepto de información de las actividades de la realeza y altas esferas, aunque no exento de un cierto posicionamiento adulador del poder, a través también de la Revista de Ciencias, Literatura y Artes, pero de 1860. Poca presentación necesita esta autora, otra de las más relevantes pioneras que escribieron en la prensa sevillana del XIX. La escritora hispano suiza (1796-1877) ya traía en las venas la tradición literaria, especialmente por parte de su madre, Frasquita Larrea, como su hija, autora de corte generalmente conservador. Extensamente estudiada desde una perspectiva literaria, no lo ha sido tanto, sin embargo, desde su faceta periodística, a pesar de ser una de las más prolíficas colaboradoras en la prensa decimonónica. No obstante, en las últimas décadas se han venido realizando diversas aproximaciones a sus colaboraciones de este tipo, como las que catalogan sus numerosos textos en las publicaciones sevillanas (Carmona González ${ }^{26}$, 1998) o profundizan en el análisis de los mismos, resaltando en su obra la influencia de sus condicionantes ideológicos y religiosos (Cantos Casenave, 1998; Benítez Alonso, 2016).

En lo que a nuestra investigación se refiere, de la faceta de Fernán Caballero como periodista-escritora de crónica de alta sociedad destacamos, dentro de la sección "Miscelánea", sus textos referentes a "El Conde de Orloff" y "El Conde Rostopchine"27.

\footnotetext{
${ }^{26}$ De gran interés resulta asimismo otra obra de catalogación de la misma autora, referida a los textos de escritoras andaluzas en la prensa de esta región en el siglo XIX (Carmona González, 1999).

${ }^{27}$ Revista de Ciencias, Literatura y Artes, vol. 6, 1860, pp. 568-572.
} 
Con respecto al primero (edecán general del emperador de Rusia), Fernán Caballero expresa su intención de ofrecer "algunos detalles sobre su familia y su persona" por el interés del lector, aprovechando como recurso informativo el gancho de actualidad del personaje, al celebrarse la efeméride del armisticio del 30 de marzo de 1814 que, tras la Batalla de París, ponía fin a la guerra de la coalición de Rusia, Austria y Prusia contra el Imperio francés, lo que obligaba a Napoleón a exiliarse. La autora se refiere al heroico linaje de Orloff, relatando valientes episodios de uno de sus antepasados en el campo de batalla y del propio conde, y resaltando que "desde cerca de dos siglos han sido los Orloffs los favoritos de los zares, y a veces instrumentos de su elevación o de su caída" (1860: 568). Para describir al conde, recurre al relato de un episodio casi inverosímil:

Cuéntanse sobre su hercúlea fuerza las más sorprendentes anécdotas (...) En una ocasión se hallaba sentado a la mesa al lado de una señora, que se extasiaba en la hermosura de las flores que componían el ramillete que adornaba la mesa, y en particular en un ramo de rosas exquisitas. El galante caballero cogió al punto el ramo para ofrecerlo a la señora, pero notando que los cabos estaban mojados buscó de prisa en qué envolverlos; no hallando otra cosa cogió un plato de plata maciza, lo hizo un cartucho cual si hubiese sido de papel, colocó en él el ramo y se lo presentó a la señora (569).

Con respecto al Conde Rostopchine, la autora (que en este caso firma con sus iniciales), se sirve, igualmente, del recurso de una percha de actualidad, en este caso, el incendio de Sebastopol por parte del príncipe Gortschakoff, para recordar al ruso Rostopchine, caudillo que incendió Moscú. A él, a pesar de que muchos se figuran que "debe ser el más terrible y feroz cosaco", se refiere como:

un hombre del mundo elegante, un hombre de mucho talento y originalidad, un fecundo autor dramático, que improvisaba piezas llenas de chistes y gracias, con las que divertía a sus amigos íntimos. Una sola fue representada con gran éxito en el teatro de Moscú; las demás las quemó. Un día una señora le pidió que le contase la historia de su vida; por respuesta le envió las siguientes páginas que vamos a traducir, y que recuerdan las sales de Gramont y el humor de Stern (569).

Y continúa con la transcripción de dicha historia ("Mis memorias o retrato al natural. Escritas en diez minutos"), que traduce del francés y en la que encontramos perlas como: "He sido atormentado por mis maestros, por los sastres que me hacían vestidos estrechos, por las mujeres, por la ambición, por los soberanos, y por los recuerdos". O: "Fui terco como una mula, caprichoso como una coqueta, alegre como un niño, perezoso como una marmota, activo como Bonaparte: todo esto según se me antojaba". Además de: "No me he entrometido nunca en casamientos ni en chismes. No he recomendado nunca ni cocinero ni médico; por consiguiente, no he atentado contra la vida de nadie". Y, al hablar de sus gustos, asegura: "Los jorobados, en ambos sexos, tenían para mí un atractivo que nunca he podido definir" (570). 
También dentro de la sección "Miscelánea" y en el mismo año, la revista recoge la crónica firmada por Fernán Caballero sobre la "Confirmación y primera Comunión de la Infanta Doña Isabel de Orleáns"28, hija de los Duques de Montpensier, en la capilla del sevillano Palacio de San Telmo. Siguiendo el más puro estilo de la información protocolaria y de agasajo oficialista de las actividades de la realeza, la crónica de la alta sociedad, publicada en un periódico de la capital y que la cabecera sevillana reproduce, se precede de una introducción en la que desde la revista se comenta que los duques, "ávidos siempre de encontrar nuevas ocasiones en las que abrir al menesteroso los tesoros inagotables de su ardiente caridad", distribuyeron "premios a la virtud" (1860: 630). Por su parte, la autora, que fue amiga personal de los duques y de la propia reina Isabel II, ya en el texto de su crónica, afirma que "no es con su oro con lo que SS. AA. RR. los Sermos. Infantes Duques de Montpensier hacen sus mayores beneficios, es con su ejemplo" (631). De su hija la infanta, la autora realiza la siguiente descripción:

estaba vestida de blanco y cubierta su cabeza con una corona de rosas blancas, la Infanta Doña Isabel, a quien la emoción había robado el habitual sonrosado de su rostro y que aparecía blanca como su blanco traje, y estaba bella de tal manera, que realizaba, no el tipo ideal de la Pery Oriental, de la Wilis Scandinava, de la Hurí del Paraíso de Mahoma, ni de la Ninfa del Olimpo Griego, sino la pura y modesta Virgen del Cielo de Dios (631).

La autora también resalta la benevolencia de los duques al narrar, con todo lujo de detalles, la celebración posterior a la ceremonia religiosa y concluyendo que "en San Telmo está "no solo el centro sino el manantial de todas las virtudes" (635). Como vemos, todo un canto a la realeza.

\section{Conclusiones}

Como resultado del análisis que hemos realizado en este trabajo, destacamos dos tipos de crónica de sociedad de autoría femenina que vemos en la prensa del mundo anglosajón y en España y, en particular, en la prensa sevillana, con algunas influencias de Mrs. Crackenthorpe (columnista inglesa de principios del siglo XVIII especializada en los ecos de sociedad en The Female Tatler) o La Pensadora Gaditana de Beatriz Cienfuegos (a mediados del mismo siglo y como observadora moral de la sociedad en España), en lo que respecta al interés por mostrar lo que sucede y cómo son las altas esferas, pero no desde la misma perspectiva crítica.

\footnotetext{
${ }^{28}$ Revista de Ciencias, Literatura y Artes, vol. 6, 1860, pp. 630-635.
} 
Encontramos así, por un lado, un modelo de crónica que habla sobre cuestiones de tipo político-social (como la prensa moral o de crítica de costumbres e instituciones, la de Los Espectadores), aunque desde un punto de vista más bien favorable al poder establecido (en el caso de las crónicas de la Condesa de Merlin), y otro de crónica de sociedad (más informativa, de las actividades de las clases altas, también dentro de una línea de mantenimiento del orden político-social existente de diferencia de clases y de concepción de la mujer como ángel del hogar, en los casos de los textos de la Condesa de Bassanville y de Fernán Caballero).

Conforme pues a estas líneas temático-ideológicas y en lo referente a los géneros, es importante señalar que en la prensa sevillana del XIX, cuando aparecen las primeras firmas femeninas en sus cabeceras periodísticas, hallamos en dos de los grandes títulos del momento (la Revista Andaluza y la Revista de Ciencias, Literatura y Artes) una crónica de sociedad que se estructura en forma de carta a las jóvenes (fórmula periodísticoliteraria muy usual en la época, como vemos también en la prensa inglesa con Mrs. Sigourney), utilizada por la Condesa de Bassanville, y otras crónicas de formato más moderno de actividades de la realeza y alta sociedad, que firma Cecilia Bölh de Faber como Fernán Caballero, además las crónicas de moda de otras autoras anónimas.

Por todo ello podemos afirmar que, aunque no de forma tan crítica con la alta sociedad del momento, la prensa sevillana decimonónica también tuvo a su particular Lady Whistledown y que, en realidad, la corporeidad de su pluma fue obra de un grupo de periodistas-escritoras, autoras pioneras en el complejo y variado entramado del panorama periodístico de la Sevilla del siglo XIX. Ellas fueron las que dieron vida en el mundo real de la prensa sevillana a este polémico pero de gran relevancia personaje de ficción, a través de unas publicaciones cuyo estudio ha constituido un campo prácticamente inexplorado hasta ahora y que, sin duda alguna, ha merecido la pena abordar en este trabajo, como parte original de una investigación que, de seguro, nos continuará deparando alguna que otra sorpresa.

\section{Referencias bibliográficas}

AGUILAR GUZMÁN, M. (2019): La era de la crónica, Santiago, Ediciones Universidad Católica de Chile.

ANDERSON, P. B. (1936): "Splendor Out of Scandal: The Lucinda-Artesia Papers in The Female Tatler", en Philological Quarterly, vol. 15, enero de 1936, pp. 286-300.

- (1931): "The History and Authorship of Mrs. Crackenthorpe's 'Female Tatler'”, en Modern Philology, vol. 28, no 3, febrero de 1931, pp. 354-360. 
BENÍTEZ ALONSO, E. M. (2016): "La novela por entregas en la prensa sevillana como arma combativa de la Iglesia frente a la violencia moral del folletín sensacionalista: La Farisea de Fernán Caballero en la Revista Sevillana Científica y Literaria", en Álvarez López, C. J.; Carmona Tierno, J. M.; Davis González, A.; González Ángel, S.; Martínez Navarro, M. R. y Rodríguez Manzano, M. (coord.), iMuerto soy!: las expresiones de la violencia en la literatura hispánica desde sus orígenes hasta el siglo XIX, Sevilla, Renacimiento, pp. 387-400.

BLUM, S. (1985): Fashions and costumes from Godey's Ladys's Book, Nueva York, Dove Publications.

CANTERLA, C. (2018): "Beatriz Manrique de Lara Alberro, Marquesa de García del Postigo, autora de La Pensadora Gaditana bajo el pseudónimo de Beatriz Cienfuegos", en Cuadernos de Ilustración y Romanticismo, no 24, 2018, pp. 741755.

- (ed. lit.) [CIENFUEGOS, B.] (1996): La Pensadora Gaditana, Cádiz, Universidad de Cádiz.

CANTERLA GONZÁLEZ, C. (1999): "El problema de la autoría de La Pensadora Gaditana", en Cuadernos de llustración y Romanticismo, no 7, 1999, pp. 29-54.

CANTOS CASENAVE, M. (1998): "Los cuentos de Fernán Caballero: una visión poética de la realidad", en Fernández Poza, M. y García Pazos, M. (coord.), Actas del Encuentro de Fernán Caballero, hoy: homenaje en el bicentenario del nacimiento de Cecilia Bóhl de Faber 1996, El Puerto de Santa María, Ayuntamiento de El Puerto de Santa María, pp. 107-126.

CAPARRÓS LERA, J. M. (2007): “Enseñar la Historia Contemporánea a través del cine de ficción”, en Quaderns de cine, no1, 2007, pp. 25-35.

CARMONA GONZÁLEZ, A. (1999): Escritoras andaluzas en la prensa de Andalucía del siglo XIX, Cádiz, Universidad de Cádiz.

- (1998): "Fernán Caballero en la prensa sevillana”, en Fernández Poza, M. y García Pazos, M. (coord.), Actas del Encuentro de Fernán Caballero, hoy: homenaje en el bicentenario del nacimiento de Cecilia Bóhl de Faber 1996, El Puerto de Santa María, Ayuntamiento de El Puerto de Santa María, pp. 275-287.

CHAVES REY, M. (1995) [1896]: Historia y bibliografía de la prensa sevillana, Sevilla, Ayuntamiento de Sevilla.

DURÁN LÓPEZ, F. (2015): Versiones de un exilio: los traductores españoles de la casa Ackermann (Londres, 1823-1830), Madrid, Escolar y Mayo. 
EGIDO LÓPEZ, T. (2002): Prensa clandestina española del siglo XVIII. "El Duende Crítico", Valladolid, Universidad de Valladolid.

ENDRES, K. L. y LUECK, T. L. (1995): Women's Periodicals in the United States: Consumer Magazines, Westport, Greenwood Press.

EZAMA GIL, A. (2009): “Criollas en París: la condesa de Merlin, Gertrudis Gómez de Avellaneda y la duquesa de la Torre", en Analecta Malacitana, vol. 32, № 2, 2009, pp. 463-482.

FERNÁNDEZ, P. (2015). No hay nación para este sexo. La Re(d)pública trasatlántica de las Letras: escritoras españolas y latinoamericanas (1824-1936), Madrid, Iberoamericana.

FERNÁNDEZ-QUINTANILLA, P. (1981): La mujer ilustrada en la España del siglo XVIII, Madrid, Ministerio de Cultura.

FERNÁNDEZ-ULLOA, T. (2018). "Algunos artículos costumbristas de Emilia Serrano en la prensa ilustrada. Estereotipos femeninos y normas de conducta en el siglo XIX", en Duraccio C., Martín Clavijo, M. y Aguilar González, J. (coord.), (Des)canonizadas. Escritoras y personajes femeninos, Sevilla, Benilde Ediciones, pp. 92-120.

FERNÁNDEZ ULLOA, T. y BENÍTEZ ALONSO, E. M. (2019): “Una pionera de la modernidad en la prensa ilustrada deI XIX: Emilia Serrano de Wilson", en Tonos digital: revista de estudios filológicos, no 36, enero de 2019, pp. 1-29. Recuperado de http://www.tonosdigital.es/ojs/index.php/tonos/article/view/2110/1037

FITTS, R. K. (1999): "The Archaeology of Middle-Class Domesticity and Gentility in Victorian Brooklyn", en Historical Archaeology, vol. 33, n1, 1999, pp. 39-62.

GOLDSMITH, M. M. (ed. lit.) [MANDEVILLE, B.] (1999): By a Society of Ladies: Essays in "The Female Tatler", Bristol, Thoemmes Press.

GRAHAM, W. (1937): "Thomas Baker, Mrs. Manley, and the 'Female Tatler'", en Modern Philology, vol. 34, no 3, febrero de 1937, pp. 267-272.

GREEN, H. (2003) [1983]: The Light of the Home: An Intimate View of the Lives of Women in Victorian America, Nueva York, Pantheon Books.

GREGORY, B. R. H. (2016): Commemorating Queen Charlotte: Race, Gender, and the Politics of Memory, 1750 to 2014. Trabajo Fin de Máster, University of North Carolina at Charlotte.

JIMÉNEZ MORELL, I. (1992): La prensa femenina en España (desde sus orígenes a 1868), Madrid, Ediciones de la Torre. 
KEISTER, L. A. y SOUTHGATE, D. E. (2012): Inequality: A Contemporary Approach to Race, Class, and Gender, Cambridge, Cambridge University Press.

MARLING, K. A. (2001): Merry Christmas! Celebrating America's Greatest Holiday, Cambridge (Massachussetts), Harvard University Press.

MERRILL, J. M. (1975): The USA: A Short History of the American Republic, Filadelfia, Lippincott.

OKKER, P. (1993): "Sarah Josepha Hale, Lydia Sigourney, and the Poetic Tradition in Two Nineteenth-Century Women's Magazines", en American Periodicals, vol. 3, 1993, pp. 32-42.

O'REILLY, B. (1883): The Mirror of True Womanhood: A Book of Instruction for Women in the World, Dublín, M. H. Gill \& Son.

PALOMO VÁZQUEZ, M. P. (2014): “Las revistas femeninas españolas del siglo XIX. Reivindicación, literatura y moda”, en Arbor, vol. 190, no 767, mayo-junio 2014. Recuperado de http://dx.doi.org/10.3989/arbor.2014.767n3001

POTVIN, J. (2009): The Places and Spaces of Fashion (1800-2007), Nueva York, Routledge.

RUIZ ACOSTA, M. J. (ed.) (2016): La Prensa Hispánica en el exilio de Londres (1810-1850), Salamanca, Comunicación Social.

SÁNCHEZ HITA, B. (2009): "Los espectadores-pensadores y su influencia en la prensa gaditana del XVIII y la Guerra de la Independencia: un modelo de éxito en una sociedad cambiante", en Cuadernos Dieciochistas, n 10, 2009, pp. 219-246.

SÁNCHEZ LLAMA, I. (2000): Galería de escritoras isabelinas: la prensa periódica entre 1833 y 1895, Madrid, Cátedra.

SMITH, J. H. (1952): "Thomas Baker and 'The Female Tatler', en Modern Philology, vol. 49, no 3, febrero de 1952, pp. 182-188.

SPACKS, P. M. (1999): Selections from the "Female Spectator" by Eliza Haywood, Oxford, Oxford University Press.

SULLIVAN, C. (1995): “Gender, text, and cross-dressing: the case of 'Beatriz Cienfuegos' and La Pensadora Gaditana", en Dieciocho, vol. 18, no 1, 1995, pp. 27-47.

WELTER, B. (1966): "The Cult of True Womanhood: 1820-1860", en American Quaterly, vol. 18, no 2, verano de 1966, pp. 151-174. 